\title{
УДК 556.5
}

DOI: $10.31774 / 2658-7890-2020-4-12-21$

\section{Н. Б. Стрельцова, С. А. Шептиев}

Новочеркасский инженерно-мелиоративный институт имени А. К. Кортунова филиал Донского государственного аграрного университета, г. Новочеркасск, Российская Федерация

\section{ОСОБЕННОСТИ ЭВТРОФИРОВАНИЯ МАЛЫХ РЕК РОСТОВСКОЙ ОБЛАСТИ}

Цель: определение влияния содержания фосфора в воде на степень эвтрофирования малых рек Грушевки и Тузлов в районе г. Новочеркасска. Материалы и методы. В качестве материалов исследования применялись данные, полученные в результате рекогносцировочного обследования малых рек в районе г. Новочеркасска и лабораторных исследований. Оценка массовой концентрации фосфатов в воде проводилась по методике РД 52.24.382-2006 «Массовая концентрация фосфатов и полифосфатов в водах. Методика выполнения измерений фотометрическим методом». В последующем материалы обрабатывались методом системного анализа и эмпирического обобщения, применялся комплексный подход к изучению мероприятий по определению степени эвтрофирования малых рек, исследовались труды российских авторов, ранее изучавших данную проблему, методом сравнения и обобщения данных. Результаты. В качестве критерия степени эвтрофикации рек часто используют концентрацию фосфора в воде. Малые реки Ростовской области - р. Тузлов и Грушевка - являются водными объектами рыбохозяйственного значения высшей категории. В районе г. Новочеркасска они подвержены высокому эвтрофированию, что обусловлено сбросом недостаточно очищенных сточных вод очистными сооружениями ООО «ПК «Новочеркасский электровозостроительный завод» и Кадамовскими очистными сооружениями. В условиях иссушения климата и снижения расхода этих рек сброс биогенных элементов в таких концентрациях может привести к их полной деградации. Выводы. Реки Грушевка и Тузлов в районе г. Новочеркасска подвержены высокому эвтрофированию. Основная причина - сброс сточных вод ООО «ПК «Новочеркасский электровозостроительный завод» и Кадамовских очистных сооружений, недостаточно очищенных от соединений фосфора. Поля фильтрации очистных сооружений не справляются с задержкой соединений фосфора, и требуются дополнительные мероприятия по очистке сбрасываемых вод.

Ключевые слова: эвтрофирование; биогенные элементы; предельно допустимая концентрация; нормирование; очистные сооружения.

\section{N. B. Streltsova, S. A. Sheptiyev}

Novocherkassk Engineering and Land Reclamation Institute - branch of the Don State Agrarian University, Novocherkassk, Russian Federation

\section{FEATURES OF SMALL RIVERS EUTROPHYING IN ROSTOV REGION}

Purpose: to determine the impact of phosphorus content in water on the degree of eutrophication of small rivers Grushevka and Tuzlov in the area of Novocherkassk. Materials and methods. The data obtained as a result of the reconnaissance survey of small rivers in the area of Novocherkassk and laboratory studies were used as research materials. The assessment of the mass concentration of phosphates in water was carried out according 
to the RD 52.24.382-2006 method "Mass concentration of phosphates and polyphosphates in waters. Photometric Measurement Method". Subsequently, the materials were processed by the method of system analysis and empirical generalization, an integrated approach to the study of measures to determine the degree of eutrophication of small rivers was applied, the works of Russian authors who had previously studied this problem were studied by method of comparison and generalization of data. Results. The concentration of phosphorus in water is often used as a criterion for the degree of eutrophication of rivers. Small rivers of Rostov region - the Tuzlov and the Grushevka are water bodies of the highest category of fishery significance. In the area of Novocherkassk they are subject to high eutrophication, which is caused by the discharge of insufficiently treated wastewater by the purification plants of LLC "PC "Novocherkassk Electric Locomotive Works" and the Kadamovskaya treatment facilities. Under the conditions of a drying out climate and a decrease in the discharge of these rivers, the discharge of nutrients in such concentrations can lead to their complete degradation. Conclusions. The rivers Grushevka and Tuzlov in Novocherkassk area are subject to high eutrophication. The main reason is the discharge of wastewater from the LLC "PC "Novocherkassk Electric Locomotive Works" and the Kadamovskaya treatment facilities, which are insufficiently purified from phosphorus compounds. Filtration fields of treatment facilities cannot cope with the retention of phosphorus compounds, and additional measures are required to clean the discharged water.

Key words: eutrophication; biogenic elements; maximum permissible concentration; rationing; purification plants.

Введение. Антропогенное эвтрофирование пресноводных водоемов и водотоков в настоящее время относят к одной из глобальных экологических проблем. Если природное эвтрофирование водоемов - это медленный процесс повышения первичной продукции экосистемы и идет на благо ее, то антропогенное эвтрофирование - это быстроразвивающийся процесс, который может привести к полной деградации водной экосистемы $[1,2]$. Проявляется эвтрофирование не только в бурном разрастании высшей водной растительности и массовом развитии фитопланктона, и прежде всего так называемых сине-зеленых водорослей, а по современной номенклатуре цианобактерий. Наиболее опасные процессы наблюдаются после отмирания организмов и их разложения. Резко падает содержание кислорода, накапливаются токсичные соединения, приводящие к гибели гидробионтов, и вода становится непригодной для водопользования.

Проблема эвтрофирования стала актуальна во второй половине XX в. Главная причина этого явления - накопление в водных объектах соединений биогенных элементов, и прежде всего соединений азота и фосфора. Роль этих элементов в повышении первичной продукции водоемов неод- 
нозначна. Если соединений азота чаще всего было достаточно, то низкое содержание соединений фосфора лимитировало развитие продуцентов. В результате загрязнения пресноводных экосистем за последние 50 лет концентрация фосфора повысилась в 100 раз и более [3-5]. Это связано с комплексным антропогенным воздействием как на сами водные экосистемы, так и на прилегающие водоохранные зоны.

Наиболее подвержены эвтрофированию малые реки. Интенсивное водопользование, сопоставимое с небольшими расходами этих рек, при чрезмерном использовании не только водных ресурсов, но и водосбора делает малые реки чрезвычайно уязвимыми [6]. Малые реки выполняют несколько функций, поддерживая равновесие и перераспределение влаги на площади водосбора.

Основным источником загрязнения водоемов являются сточные воды. Создание отстойников, очистных сооружений снизило степень загрязнения этой категории сточных вод. В то же время возросла доля загрязненных вод, которые формируются в пределах водосборных бассейнов малых рек. Это прежде всего поверхностный сток с сельскохозяйственных угодий, содержащий минеральные удобрения, ядохимикаты и биогенные вещества.

Целью исследования стало определение влияния содержания фосфора в воде на степень эвтрофирования малых рек Грушевки и Тузлов в районе г. Новочеркасска.

Материалы и методы. В качестве материалов исследования применялись данные, полученные в результате рекогносцировочного обследования малых рек в районе г. Новочеркасска и лабораторных исследований. Оценка массовой концентрации фосфатов в воде проводилась по методике РД 52.24.382-2006 «Массовая концентрация фосфатов и полифосфатов в водах. Методика выполнения измерений фотометрическим методом». В последующем материалы обрабатывались методом системного анализа и эмпирического обобщения, применялся комплексный подход к изучению 
мероприятий по определению степени эвтрофирования малых рек, исследовались труды российских авторов, ранее изучавших данную проблему, методом сравнения и обобщения данных.

Результаты и обсуждения. В Ростовской области примером малых рек, подверженных антропогенному эвтрофированию, являются Грушевка и Тузлов. Бассейны этих рек входят в состав водосборного бассейна Дона и, как следствие, влияют на степень его загрязнения. Площадь водосбора р. Тузлов равна 4680 км². Впадает река в протоку Аксай, в один из самых крупных притоков Нижнего Дона. По данным областной санэпидстанции, p. Тузлов с притоками в настоящее время используется населением для орошения приусадебных участков, садов и огородов, самодеятельного отдыха, купания и спортивного рыболовства.

На территории бассейна имеются комплексные, ландшафтные, ботанические и водные государственные памятники природы: «Агролес», урочище «Золотая криница», пруд и роща им. 20-летия РККА, Персиановская заповедная степь, Верховое водохранилище-охладитель ТЭЦ им. Артема.

Отбор воды на орошение, нужды сельского хозяйства и промышленности, строительство многочисленных прудов и водохранилищ, перегораживающих сооружений примитивного типа привели к зарегулированию стока р. Тузлов и ее притоков, к их обмелению и заилению.

На берегах р. Тузлов и ее притоков расположены наиболее крупные населенные пункты, находящиеся на территории бассейна. Поэтому рекреационное значение рек как мест отдыха населения у воды велико. Однако в настоящее время в связи с заилением и сбросом сточных и шахтных вод в реки вода рек не удовлетворяет санитарным и эстетическим требованиям, как и прибрежные зоны в черте населенных пунктов. На современном уровне развития хозяйства в бассейне р. Тузлов в год 75\% обеспеченности стока отмечаются дефициты водопотребления в среднем течении реки (до впадения р. Большой Несветай) в размере 0,63 млн м³ (данные 2-ТП (водхоз)) и 1,63 млн м³ (расчетный за 1999 г.). 
Грушевка - это левый и крупнейший приток р. Тузлов. Длина ее небольшая, 82 км, площадь водосборного бассейна 941 км². На реке расположены г. Шахты, Промышленный район г. Новочеркасска и целый ряд сельских поселений. Этот район - один из самых экономически освоенных речных водосборов на территории Ростовской области. Здесь развита промышленность, угледобыча, сельское хозяйство, транспорт. При очень небольшом расходе р. Грушевки сброс сточных вод, включая шахтные воды из балки Аюта, достигает 32095 тыс. м³/год.

В качестве критерия степени эвтрофикации рек часто используют концентрацию фосфора в воде. Реки Тузлов и Грушевка являются водными объектами рыбохозяйственного значения высшей категории. Здесь находятся нерестилища ценного вида рыбца и занесенной в Красную книгу шемаи. Предельно допустимый уровень содержания фосфора в воде для таких водных объектов установлен в 0,2 мг/л. Превышение этого значения свидетельствует об антропогенном эвтрофировании.

Концентрация фосфора в воде рек исследуемого района значительно варьирует (рисунок 1). По полученным в ходе исследований данным, а также по сведениям ежегодника [7] и данным предыдущих исследований $[8,9]$, содержание этого элемента напрямую зависит от сброса сточных вод очистными сооружениями. В исследуемом районе таких участков два. Это район очистных сооружений ООО «ПК «Новочеркасский электровозостроительный завод» (ООО «ПК «НЭВЗ») (х. Веселый) и Кадамовских очистных сооружений (КОС).

Пропускная способность сооружений ООО «ПК «НЭВЗ»: по проекту $22000 \mathrm{~m}^{3} /$ сут, фактически - 11400,28 м³/сут. В составе сооружений есть поля фильтрации, они предназначены для биологической очистки сточных вод. Очистка сточных вод происходит в процессе фильтрации их через почву. При этом задерживаемые органические загрязнения вместе с бактериями обволакивают частицы почвы, образуют биологическую пленку. Площадь поля фильтрации составляет 210 га при количестве карт 78. Поля 
фильтрации заливаются согласно графику из расчета 80-100 м³ сточной жидкости на 1 га/сут. Очищенная вода по обводным каналам попадает в выпуски и потом в р. Тузлов и Грушевку. Три выпуска отводят очищенные сточные воды в р. Тузлов, пять выпусков в р. Грушевку.

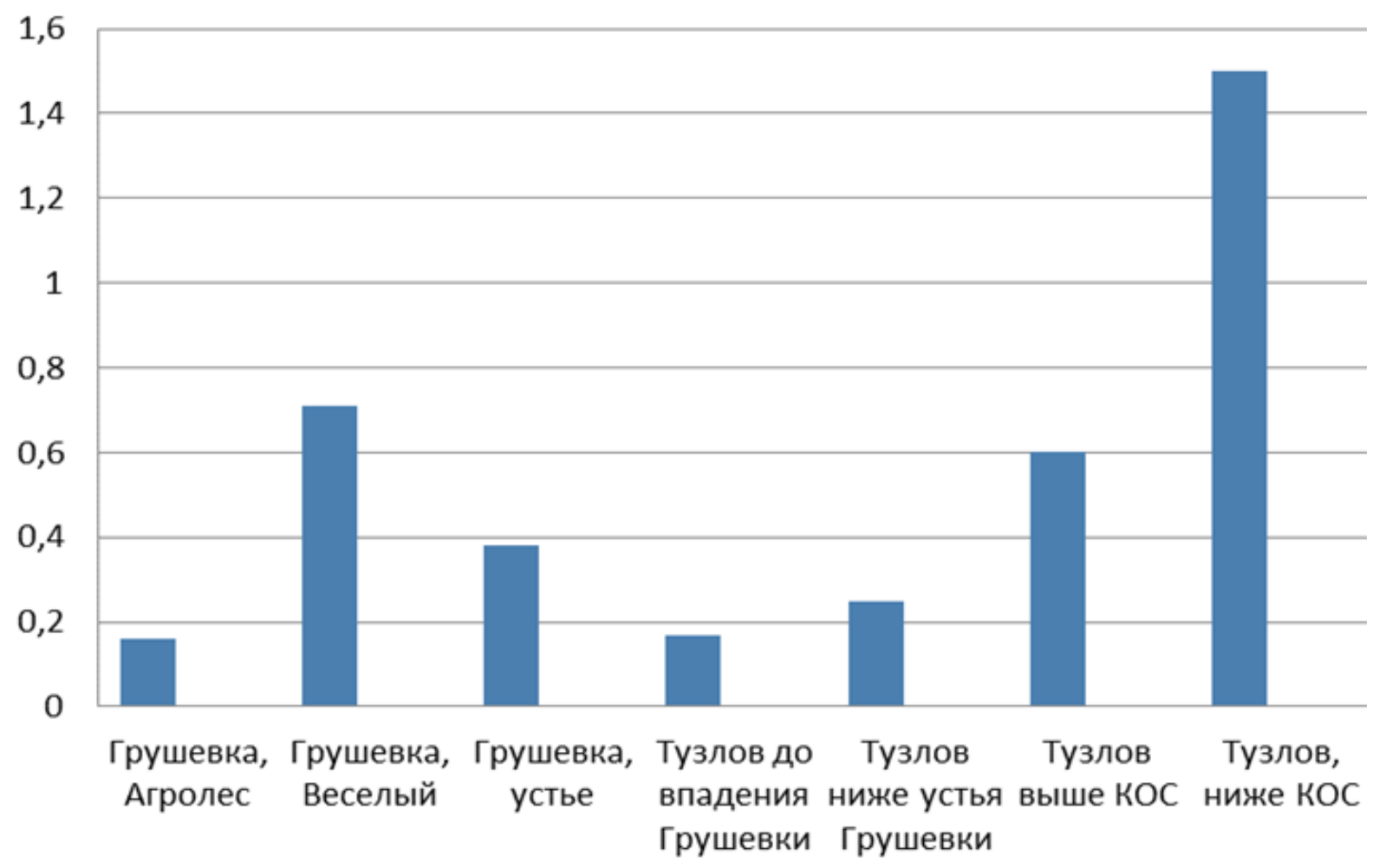

\section{Рисунок 1 - Содержание фосфатов в воде р. Грушевки и Тузлов (мг/л)}

Согласно полученным данным, если концентрация фосфора в воде p. Грушевки до этих очистных ниже ПДК ние более чем в 3 раза (рисунок 1). К устью р. Грушевки концентрация фосфора снижается, но остается все равно выше нормативной.

Воды Грушевки в районе г. Новочеркасска являются одной из причин загрязнения р. Тузлов. Концентрация фосфора до впадения р. Грушевки была ниже предельно допустимого значения, а после смешения с водами Грушевки отмечается превышение.

Наибольшее влияние на загрязнение в нижнем течении р. Тузлов оказывают КОС. Они предназначены для обработки бытовых и промышленных сточных вод г. Новочеркасска. Включают две линии очистки: биологическую и механическую. Фактическая производительность очистных соору- 
Экология и водное хозяйство, № 4(07), 2020 г., [12-21]

жений канализации (ОСК) «Кадамовские» составляет 25-30 тыс. м³/сут [10]. После серии очистных мероприятий вода из отстойников попадает в биопруды, а далее через выпуск, выполненный в виде открытого железобетонного канала длиной 800 м, с левого берега отводится в р. Тузлов. Этот выпуск сточных вод поверхностный, сосредоточенный, территориально находится в черте г. Новочеркасска.

Место выпуска очищенных сточных вод ОСК расположено на 4 км выше устья р. Тузлов. Несмотря на все проводимые мероприятия по очистке сточных вод, концентрация фосфора в реке ниже сброса превышает нормативную более чем в 7 раз. Наиболее загрязненная биогенными элементами зона р. Тузлов ниже сброса сточных вод КОС оценивается как политрофная.

Выводы. Таким образом, p. Грушевка и Тузлов в районе г. Новочеркасска подвержены высокому эвтрофированию. Основная причина - сброс сточных вод ООО «ПК «НЭВЗ» и Кадамовских очистных сооружений, недостаточно очищенных от соединений фосфора. Поля фильтрации этих сооружений не справляются с очисткой от соединений фосфора, и требуются дополнительные мероприятия по очистке сбрасываемых вод. В условиях иссушения климата и снижения расхода этих рек сброс биогенных элементов в таких концентрациях может привести к их полной деградации.

\section{Список использованных источников}

1 Науменко, М. А. Эвтрофирование озер и водохранилищ / М. А. Науменко. СПб.: Изд-во РГГМУ, 2007. - 100 с.

2 Хрисанов, Н. И. Управление эвтрофированием водоемов / Н. И. Хрисанов, Г. К. Осипов. - СПб.: Гидрометеоиздат, 1993. - 274 с.

3 Оценка экологического состояния водоемов комплексного назначения в составе агрогидробиоценоза / Ю. М. Субботина, В. П. Захаркин, Л. А. Розумная, А. В. Гапоненко. - М.: Изд-во РГСУ, 2008. - 142 с.

4 Кутявина, Т. И. Изучение процессов эвтрофикации водных объектов Кировской области: автореф. дис. ... канд. биол. наук: 03.02.08 / Кутявина Татьяна Игоревна. Киров, 2017. - 24 с.

5 Яценко-Степанова, Т. Н. Основные подходы к определению трофности природных водоемов / Т. Н. Яценко-Степанова, Н. В. Немцева, М. Е. Игнатенко // Бюллетень Оренбургского научного центра УрО РАН [Электронный ресурс]. - 2014. - № 1. - 7 с. - Режим доступа: http:elmag.uran.ru:9673/magazine/Numbers/2014-1/Articles/Yatsenko-Stepanova\%20TNsoavt-2014-1.pdf. 
6 Международное десятилетие действий «Вода для жизни»: информ.-библиогр. пособие / сост.: Н. В. Кусова; Орл. обл. публ. б-ка им. И. А. Бунина. - Орел, 2009. - 41 с.

7 Качество поверхностных вод Российской Федерации. Ежегодник. 2018 [Электронный ресурс] / Е. Е. Лобченко [и др.]; под ред. М. М. Трофимчука. - Ростов н/Д., 2019. 560 с. - Режим доступа: http:gidrohim.com/sites/default/files/Ежегодник\%202018_2.pdf, 2020.

8 Стрельцова, Н. Б. Особенности формирования химического состава вод и донных отложений рек в районе г. Новочеркасска / Н. Б. Стрельцова, А. А. Гончарова, 3. Р. Бакиев // Мелиорация и водное хозяйство. Вып. 16. Инновационные технологии мелиорации, водного и лесного хозяйства юга России: материалы Всерос. науч.-практ. конф. (Шумаковские чтения) с междунар. участием, 6-23 нояб. 2018 г. / Новочеркас. инж.-мелиоратив. ин-т Донского ГАУ. - Новочеркасск: Лик, 2018. - Ч. 2. - С. 176-179.

9 Стрельцова, Н. Б. Особенности химического состава донных отложений р. Грушевка и Тузлов / Н. Б. Стрельцова, 3. Р. Бакиев // Состояние и перспективы развития агропромышленного комплекса: юбилейн. сб. науч. тр. XIII Междунар. науч.практ. конф., посвящ. 90-летию ДГТУ. - Ростов н/Д.: ДГТУ-Принт, 2020. - С. 176-179.

10 Проект схемы водоснабжения и водоотведения г. Новочеркасска [Электронный ресурс]. - Режим доступа: https:novochgrad.ru/public/din_files/utverzhdennyj_ proekt_shemy_vodosnabzheniya_i_vodootvedeniya_goroda_novocherkasska_na_perspektivu _do_2023_goda.pdf, 2020.

\section{References}

1 Naumenko M.A., 2007. Evtrofirovanie ozer $i$ vodokhranilishch [Eutrophication of Lakes and Reservoirs]. St. Petersburg, Russian State Medical University Publ., 100 p. (In Russian).

2 Khrisanov N.I., Osipov G.K., 1993. Upravlenie evtrofirovaniem vodoemov [Management of Water Bodies Eutrophication]. St. Petersburg, Gidrometeoizdat Publ., 274 p. (In Russian).

3 Subbotina Yu.M., Zakharkin V.P., Rozumnaya L.A., Gaponenko A.V., 2008. Otsenka ekologicheskogo sostoyaniya vodoemov kompleksnogo naznacheniya v sostave agrogidrobiotsenoza [Assessment of the Ecological State of Multi-Purpose Water Bodies in the Composition of Agrohydrobiocenosis]. Moscow, Russian State Social University Publ., 142 p. (In Russian).

4 Kutyavina T.I., 2017. Izuchenie protsessov evtrofikatsii vodnykh ob'ektov Kirovskoy oblasti. Avtoref. dis. kand. biol. nauk [Study of eutrophication processes of water bodies in Kirov region. Abstract of cand. biol. sci. diss.]. Kirov, 24 p. (In Russian).

5 Yatsenko-Stepanova T.N., Nemtseva N.V., Ignatenko M.E., 2014. Osnovnye podkhody $k$ opredeleniyu trofnosti prirodnykh vodoemov [Basic approaches to determining the trophicity of natural water bodies]. Byulleten' Orenburgskogo nauchnogo tsentra UrO RAN [Bull. of Orenburg Scientific Center of the Ural Branch of the Russian Academy of Sciences], no. 1, 7 p., available: http:elmag.uran.ru:9673/magazine/Numbers/2014-1/Articles/YatsenkoStepanova\%20TN-soavt-2014-1.pdf. (In Russian).

6 Kusova N.V., 2009. Mezhdunarodnoe desyatiletie deystviy "Voda dlya zhizni": inform.-bibliogr. posobie [International Decade for Action "Water for Life". Informational bibliography manual]. Orel Region Public Library named after I.A. Bunin, Orel, 41 p. (In Russian).

7 Lobchenko E.E. [et al.], 2019. Kachestvo poverkhnostnykh vod Rossiyskoy Federatsii. Ezhegodnik. 2018 [Surface Water Quality in the Russian Federation. Yearbook 2018]. Rostov-on-Don, 560 p., available: http:gidrohim.com/sites/default/files/ Ежегодник\%202018_2.pdf [accessed 2020]. (In Russian).

8 Streltsova N.B., Goncharova A.A., Bakiev Z.R., 2018. Osobennosti formirovaniya khimicheskogo sostava vod $i$ donnykh otlozheniy rek $v$ rayone $g$. Novocherkasska [Features of formation of chemical composition of waters and bottom sediments of rivers in the area of 
Novocherkassk]. Melioratsiya $i$ vodnoe khozyaystvo. Vyp. 16. Innovatsionnye tekhnologii melioratsii, vodnogo $i$ lesnogo khozyaystva yuga Rossii: materialy Vseros. nauchnoprakticheskoy konferentsii (Shumakovskie chteniya) s mezhdunar. uchastiem [Reclamation and Water Management. Iss. 16. Innovative technologies of Land Reclamation, Water and Forestry in the South of Russia: Proc. of All-Russian Scientific Practical Conference (Shumakov Readings) with International Participation]. Novocherkassk Engineering and Land Reclamation Institute of the Don State Agrarian University, Novocherkassk, Lik Publ., 2018, pt. 2, pp. 176-179. (In Russian).

9 Streltsova N.B., Bakiev Z.R., 2020. Osobennosti khimicheskogo sostava donnykh otlozheniy r. Grushevka i Tuzlov [Features of chemical composition of bottom sediments of the rivers Grushevka and Tuzlov]. Sostoyanie i perspektivy razvitiya agropromyshlennogo kompleksa: yubileyny sbornik nauch. trudov XIII Mezhdunarodnoy nauchno-prakticheskoy konferentsii, posvyashchennoy 90-letiyu DGTU [State and Prospects of Development of Agro-Industrial Complex: Proc. of Jubilee XIII International Scientific Practical Conf., dedicated to the $90^{\text {th }}$ anniversary of DSTU]. Rostov-on-Don, DGTU-Print Publ., pp. 176-179. (In Russian).

10 Proekt skhemy vodosnabzheniya $i$ vodootvedeniya Novocherkasska [Draft Water Supply and Sewerage Scheme for Novocherkassk], available: https:novochgrad.ru/public/ din_files/utverzhdennyj_proekt_shemy_vodosnabzheniya_i_vodootvedeniya_goroda_novocherka sska_na_perspektivu_do_2023_goda.pdf [accessed 2020].(In Russian).

\section{Стрельцова Наталья Борисовна}

Ученая степень: кандидат биологических наук

Ученое звание: доцент

Должность: доцент

Место работы: Новочеркасский инженерно-мелиоративный институт имени А. К. Кортунова - филиал федерального государственного бюджетного образовательного учреждения высшего образования «Донской государственный аграрный университет»

Адрес организации: ул. Пушкинская, 111, г. Новочеркасск, Ростовская область, Российская Федерация, 346428

E-mail: stre-natalya@yandex.ru

\section{Streltsova Natalya Borisovna}

Degree: Candidate of Biological Sciences

Title: Associate Professor

Position: Associate Professor

Affiliation: Novocherkassk Engineering and Land Reclamation Institute - branch of the Don State Agrarian University

Affiliation address: st. Pushkinskaya, 111, Novocherkassk, Rostov region, Russian Federation, 346428

E-mail: stre-natalya@yandex.ru

\section{Шептиев Семен Анатольевич}

Должность: студент

Место работы: Новочеркасский инженерно-мелиоративный институт имени А. К. Кортунова - филиал федерального государственного бюджетного образовательного учреждения высшего образования «Донской государственный аграрный университет»

Адрес организации: ул. Пушкинская, 111, г. Новочеркасск, Ростовская область, Российская Федерация, 346428

E-mail: sema.sheptiev@mail.ru

\section{Sheptiyev Semen Anatolyevich}

Position: Undergraduate

Affiliation: Novocherkassk Engineering and Land Reclamation Institute - branch of the Don 
Экология и водное хозяйство, № 4(07), 2020 г., [12-21]

State Agrarian University

Affiliation address: st. Pushkinskaya, 111, Novocherkassk, Rostov region, Russian Federation, 346428

E-mail: sema.sheptiev@mail.ru

Поступила в редакцию 16.10.2020

После доработки 23.11.2020

Принята к публикации 27.11.2020 